\title{
CONFLITOS SOCIOAMBIENTAIS NA GESTÃO DO PARQUE NACIONAL DOS LENÇÓIS MARANHENSES: O CASO DAS COMUNIDADES TRATADA DE CIMA, TRATADA DE BAIXO E BURITIZAL ${ }^{1}$
}

\author{
SOCIO-ENVIRONMENTAL CONFLICTS IN THE MANAGEMENT OF \\ THE LENÇOIS MARANHENSES NATIONAL PARK: THE CASE OF THE \\ COMMUNITIES TRATADA DE CIMA, TRATADA DE BAIXO AND BURITIZAL
}

\author{
CONFLICTOS SOCIOAMBIENTALES EN LA GESTIÓN DEL PARQUE \\ NACIONAL DE LOS LENÇÓIS MARANHENSES: EL CASO DE LAS \\ COMUNIDADES TRATADA CIMA, TRATADA DE BAIXO Y BURITIZAL \\ Ademir Terra - Universidade Estadual do Maranhão - São Luís - Maranhão - Brasil \\ ademir.terra@outlook.com
}

\begin{abstract}
Resumo
0 Parque Nacional dos Lençóis Maranhenses (PNLM) faz parte do grupo de Unidades de Proteção Integral e, como previsto pelo Sistema Nacional de Unidades de Conservação da Natureza (SNUC), na categoria de parque, tem como objetivo preservar a natureza, sendo admitido apenas o uso indireto dos seus recursos naturais. Por ter sido criado em um contexto histórico em que predominava a concepção dicotômica sociedade-natureza, a presença do ser humano habitando em seu interior não é permitida. Todavia, como não foi providenciada a retirada de centenas de famílias que residem na área desde o final do século XIX, por força da legislação, elas passaram a sofrer restrições que implicam a impossibilidade de manutenção das atividades até então praticadas de acordo com seus padrões culturais tradicionais, sem que thes fossem oferecidas alternativas compatíveis com as necessidades de subsistência e reprodução, nem com a manutenção e preservação de seu gênero de vida. Em razão disso, os conflitos preexistentes foram potencializados após a criação do parque, resultando no surgimento de outros, mais complexos, os quais nos propomos a analisar neste artigo.
\end{abstract}

Palavras-chave: Conflitos socioambientais, Parque Nacional, Lençóis Maranhenses.

\begin{abstract}
The national park of Lençóis Maranhenses - PNLM, makes part of the group of Integral Protection Units, and as provided by Nature Conservation Units System - SNUC, In the category of park, aims to preserve nature, with only the indirect use of its natural resources. Because it was created in a historical context in which prevailed the dichotomous conception of society - nature, the presence of the human being living in its interior is not allowed. However, as it was not arranged the removal of hundreds of families residing in the area since the end of the 19th century due to the legislation, they were subject to restrictions that imply the impossibility of maintaining the activities practiced according to their cultural traditional standards so far, without being offered alternatives compatible with the necessities of subsistence and reproduction, nor with the maintenance and preservation of their kind of life. As a result, the preexisting conflicts were strengthened after the creation of the Park, resulting in the emergence of others, more complex, which we propose to analyze in this article.
\end{abstract}

Keywords: Social-enviromental conflicts, National Park, Lençois Maranhenses. 


\section{Resumen}

El Parque Nacional dos Lençóis Maranhenses (PNLM) es parte del grupo de Unidades de Protección Integral del Medio Ambiente y, conforme está previsto por el Sistema Nacional de las Unidades de Conservación de la Naturaleza (SNUC), la categoría de este parque tiene como objetivo preservar la naturaleza y sólo es autorizado el uso indirecto de los recursos naturales. Por haber sido creado en el contexto histórico en el que predominaba la dicotomía sociedad-naturaleza, no se permite la presencia del ser humano como habitante en su interior. Sin embargo, como no se hizo la evacuación de cientos de familias que vivían en este lugar desde finales del siglo XIX, por causa de la legislación, esas familias empezaron a sufrir restricciones relacionadas a la mantención de sus actividades, hasta aquel momento practicadas de acuerdo con sus padrones culturales y tradicionales, sin que les fuesen ofrecidas alternativas compatibles con las necesidades de sobrevivencia y reproducción, ni con la mantención de la preservación de su género de vida. Por causa de los conflictos pre-existentes, después de la creación del parque, surgieron otros conflictos más complicados que, aquí, intentamos analizar.

Palabras clave: Conflictos socio-ambientales, Parque Nacional, Lençóis Maranhenses.

Introdução

A gestão da biodiversidade no Brasil apresenta uma série de desafios que nos forçam a admitir a necessidade de tomar ciência de um extenso conjunto de conhecimentos. São desafios fundamentalmente disciplinares que, numa perspectiva das ciências humanas, buscam interpretar os conflitos sociais como importante elemento de análise, com potencial de contribuição para a gestão de áreas protegidas no Brasil.

A criação dos Parques Nacionais (PARNA) constitui uma medida fundamental para gerir a biodiversidade em âmbito nacional e global. Essa categoria de manejo é essencial para a proteção da natureza no país, representando a possibilidade de conservação in situ, premissa que foi reafirmada pela Convenção sobre a Diversidade Biológica e reconhecida como uma das prioridades para a conservação da biodiversidade mundial.

Entre os 71 Parques Nacionais existentes no Brasil hoje, incluídos na categoria de Unidades de Proteção Integral definidas na Lei no 9.985/2000, que institui o Sistema Nacional de Unidades de Conservação da Natureza (SNUC), está o Parque Nacional dos Lençóis Maranhenses (PNLM) ${ }^{2}$ (Mapa 1), que faz parte das 320 Unidades de Conservação (UC) federais geridas pelo Instituto Chico Mendes de Conservação da Biodiversidade (CMBio). Localizado na região nordeste do estado do Maranhão, possui uma área de 156.584 ha e um perímetro de $270 \mathrm{~km}$, ocupando parte do território dos municípios de Barreirinhas (44,86\%), Santo Amaro do Maranhão (42,15\%) e Primeira Cruz (6,89\%). De acordo com Castro (2012, p. 151), “o PNLM foi sugerido como um espaço a se constituir em espaço de conservação a partir do projeto RADAM-BRASIL, na década de 1970”. 


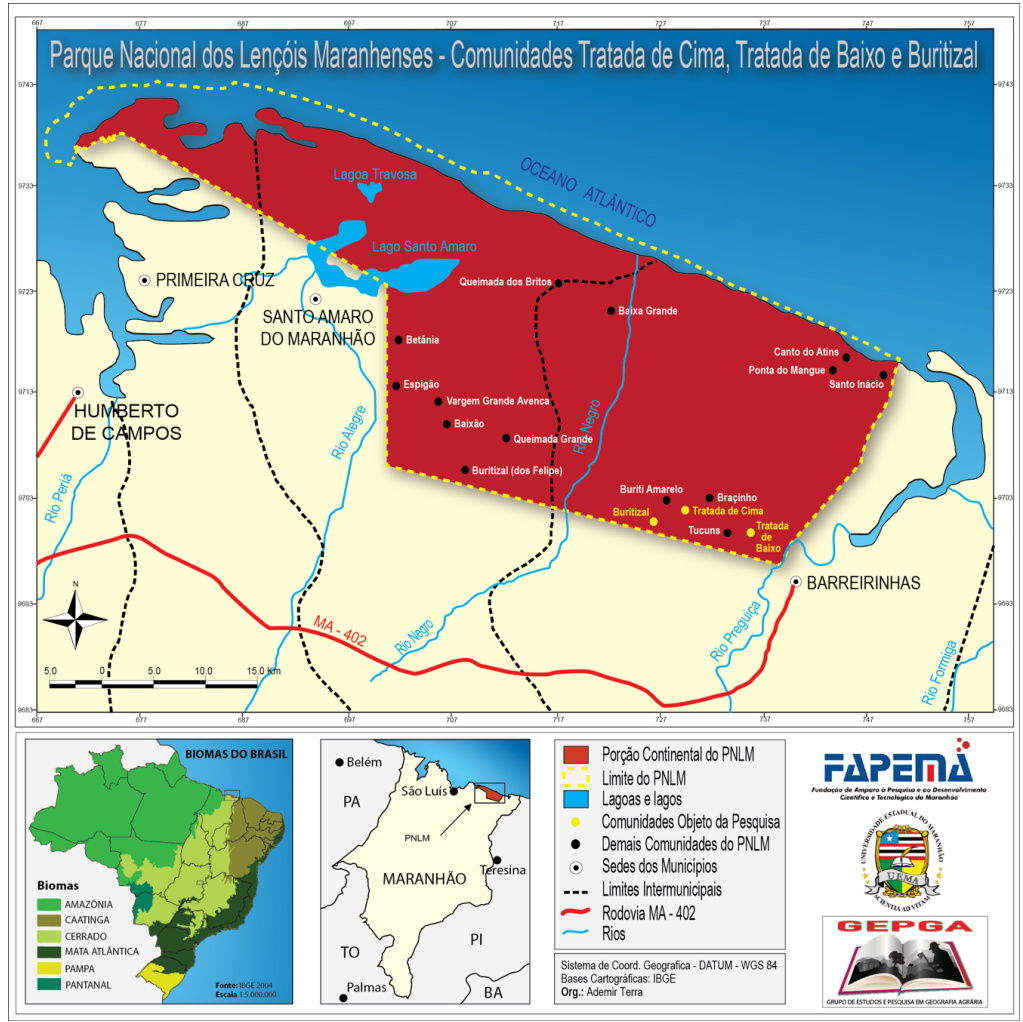

Mapa 1 - Localização Geográfica das Comunidades Tratada de Cima, Tratada de Baixo e Buritizal no Parque Nacional dos Lençóis Maranhenses (PNLM)

Fonte: Terra, 2016

Inserido no bioma costeiro marinho, com ecossistemas de mangue, restinga e dunas, o PNLM abriga em seu interior aproximadamente 90.000 ha de dunas livres e lagoas interdunares de água doce, além de grandes áreas de restinga e de costa oceânica. A faixa de dunas avança, a partir da costa, de 5 a $25 \mathrm{~km}$ em direção ao interior. Na região, encontra-se a nascente do rio Preguiças, que corta o parque até a sua foz, no oceano Atlântico.

Este texto objetiva discutir a situação dos atores sociais e interpretar os principais conflitos socioespaciais vividos pelas famílias que habitam três das 17 comunidades existentes no PNLM -Tratada de Cima, Tratada 
de Baixo e Buritizal -, localizadas no município de Barreirinhas, na parte ocidental do parque, os quais foram potencializados após a criação das Unidades de Conservação (UC) no início dos anos 1980.

Para tanto, desenvolveram-se investigações teóricas e empíricas, através da análise documental e da literatura ligada à questão dos conflitos socioambientais. Foram realizados também trabalhos de campo nas comunidades, quando os sujeitos políticos envolvidos no processo foram entrevistados - das 74 famílias residentes nas comunidades alvo da pesquisa, entrevistou-se integrantes de 22 (aproximadamente 30\% das famílias), três líderes comunitários (um de cada comunidade), três donos de agência de turismo, o secretário municipal de Agricultura, Pesca e Desenvolvimento do município de Barreirinhas, além de dois técnicos do ICMBio. As abordagens foram predominantemente qualitativas, com a utilização de entrevistas semiestruturadas, caracterizadas por Denker (2000, p. 137) como "uma comunicação verbal entre duas ou mais pessoas, com um grau de estruturação previamente definido, cuja finalidade é a obtenção de informações de pesquisa e de novas consultas documentais". Esse instrumento, segundo a autora, "permite maior liberdade do pesquisador”, pois admite a adição de perguntas não previstas, a depender do teor das respostas e das reações dos entrevistados. A pesquisa, dessa forma, possibilitou a compreensão da realidade por meio de uma relação dinâmica entre o mundo real e o sujeito, uma vez que o conhecimento não é separado em partes e está em constante movimento.

\section{Conflitos socioambientais no Parque Nacional dos Lençóis Maranhenses}

Os conflitos ambientais ou socioambientais só recentemente têm sido objeto de pesquisas nas ciências humanas e sociais, ainda que tais problemas já estivessem relacionados às mais diversas temáticas na produção de conhecimento científico.

Os estudiosos dessa modalidade de conflito, ligados às Ciências Sociais, têm buscado organizá-lo como uma categoria de análise, que incorpora a questão ambiental. Por exemplo: na Ciência Política, os estudos relacionados aos movimentos sociais ambientais; na Geografia, os conflitos entre sociedade e natureza dentro do espaço geográfico; posteriormente, na Antropologia, os estudos atinentes às comunidades tradicionais, sob um viés da ecologia política; e, na Sociologia, com a constituição de um novo ramo denominado Sociologia Ambiental. 
Como se pode evidenciar, a análise dos conflitos socioambientais se realiza em um campo polissêmico marcado por disputas, que implicam relações de poder que permeiam as práticas sociais. Os conflitos surgem quando os territórios apropriados por grupos que mantêm diferentes modos de vida e de relação com o meio ambiente entram em confronto com a dominação exercida pelo poder do capital. Nos espaços onde eles ocorrem não estão em disputa unicamente os bens e os serviços ecossistêmicos, mas também as diferentes formas de apropriação dos territórios, assim como a manutenção da cultura, como veremos doravante ao analisarmos tais conflitos no PNLM.

O PNLM, embora tenha sido criado pelo Decreto Federal $\mathrm{n}^{\circ}$ 86.060, de 2 de junho de 1981, foi inserido no grupo das Unidades de Proteção Integral (UPI) a partir da aprovação da Lei $\mathrm{n}^{0}$ 9.985, com o objetivo básico de "preservar a natureza, sendo admitido apenas o uso indireto dos seus recursos naturais" (Brasil, 2000), como preconiza o inciso VI do seu artigo $2^{\circ}$. Num contexto histórico em que predominava a concepção dicotômica sociedade-natureza, a criação de tal área pressupõe a preservação de espécies da flora e da fauna, restringindo o acesso a seus recursos naturais, assim como do seu entorno, definido como zona de amortecimento, com condicionantes ambientais para sua utilização e proibição, em tese, da existência de populações humanas em seu interior.

Por força dessa legislação, estabeleceu-se uma série de restrições às comunidades tradicionais que habitam o interior do parque e que se servem dos recursos naturais e dos atributos do lugar para sua subsistência, por meio de atividades como pesca, roça, pecuária extensiva e extrativismo, entre outras. O conjunto de exigências impostas pelo documento legal impactou uma população que, desde as grandes secas do final do século XIX, se instalou nas bordas dos Lençóis e, a partir de então, vem desenvolvendo uma prática de subsistência na área, habituada às suas tradições nos padrões de uso e ocupação do solo. A medida teve como consequência direta o acirramento dos conflitos preexistentes e o afloramento de outros, mais complexos, com reflexos na gestão do território do parque.

Quando da elaboração do Plano de Manejo do Parque, o MMA/ IBAMA (2004, p. 5) constatou a existência de aproximadamente 215 famílias que o ocupavam na condição de posseiros. Segundo Castro (2012), a ocupação dessa porção do território maranhense é ainda mais antiga, remontando ao período colonial: 
[...] os resultados do processo de ocupação da porção ocidental da costa maranhense foram núcleos comunitários esparsos, como ilhas, de baixa densidade populacional, com duas frentes distintas, que convém destacar. Uma mais antiga [...], associada aos processos de povoamento inicial da colônia, onde o europeu enfrentou o índio, aniquilando-o ou fundindo-o em um novo território não mais indígena, e outra, mais recente, iniciada no final do século XIX, no qual novos espaços são ocupados algures, onde o migrante que escapa dos repetitivos ciclos da seca se fixa, constituindo inicialmente uma territorialidade sertaneja que evolui para o que encontramos hoje (Castro, 2012, p.153).

O relatório da International Union for Conservation of Nature (IUCN, 1993) recomenda que sejam evitados os conflitos e interpretadas as bases da cultura local para o processo de tomada de decisões. Da mesma forma, o SNUC também preconiza que as populações tradicionais devem ter seus meios de vida e cultura protegidos e valorizados, de modo que a implementação de uma UC deve ser feita de forma democrática, mediante consultas populares.

Pereira (2005) assinala, todavia, que a criação e a gestão das UC brasileiras ainda têm se dado de forma centralizada, com deliberações "de cima para baixo" e restrita participação pública. O processo de criação das áreas a serem preservadas - que em geral se resume, no que concerne à população envolvida, à transferência de informações ou consultas - não abre espaço para a agregação de valores fundamentais à racionalidade ambiental e aos valores humanistas, a qual, se considerada, permitiria uma gestão participativa e democrática dos recursos ambientais. Em muitos casos, as populações locais só ficam sabendo que sua propriedade está inserida numa Unidade de Conservação após o fato consumado.

Os habitantes da área mantêm um estilo de vida tradicional, essencial para a conservação e a utilização sustentável da biodiversidade. Esta, como apontam Diegues e Arruda (2001, p.15), "não é só um produto da natureza, mas em muitos casos é produto da ação das sociedades e culturas humanas, em particular das sociedades tradicionais não industriais. É também uma construção cultural e social [...]”. Dissociar os moradores, portanto, do processo de conservação pode gerar um resultado contrário aos propósitos conservacionistas.

Além das características gerais que marcam a instalação e a gestão das UC, o caso do PNLM inclui outros aspectos, também em razão de haver um interstício de 19 anos entre a criação do parque 
(1981) e sua transformação em UPI pela lei que instituiu o SNUC. As mudanças inerentes à medida geraram, assim, uma situação que dificulta a permanência das comunidades tradicionais na área protegida, com a ocorrência de conflitos que culminaram em desobediência civil.

A despeito desses pontos de inflexão, a abordagem participativa prevista na concepção do SNUC representa, no entanto, o reconhecimento, crescente no mundo todo, dos direitos das populações indígenas e de outras populações tradicionais, bem como da importância do seu conhecimento ecológico para a gestão ambiental.

Não existe, porém, uma definição universalmente aceita para caracterizar o que se entende por populações tradicionais. No sentido mais literal, o termo implica uma longa residência em determinada área (Colchester, 1997). Diversos autores incluem os seguintes aspectos ao conceituar tais populações: dependem diretamente de recursos naturais do ambiente em que habitam para sua subsistência e distinguem-se como sociedades não industriais, geralmente com baixa orientação tecnológica (Berkes, 1999). Além disso, exibem amplo conhecimento sobre os processos ecológicos locais, formado de maneira empírica (Holling et al., 1998). No Brasil, são exemplos de tais populações as comunidades indígenas, os pescadores artesanais e trabalhadores extrativistas, entre outros, caracterizados por sua dependência direta em relação ao ambiente em que habitam (Arruda, 2000). Ainda de acordo com Berkes (1999, p.8), da ligação próxima entre a comunidade e o território que ela ocupa, resulta o conhecimento ecológico tradicional (CET), definido por ele como o "corpo de conhecimento, práticas e valores acumulados, desenvolvidos através de processos adaptativos e transferidos de geração em geração por meios culturais, sendo relacionado às relações entre sociedades e entre sociedade e o ambiente".

O território é o recorte espacial definido por relações de apropriação, poder e de controle sobre recursos e fluxos, baseado em aspectos políticos, econômicos e culturais (Haesbaert, 2006; Saquet, 2007; Spósito, 2004). A territorialidade é, pois, um processo que envolve não somente a forma de ocupação física do espaço, mas também manifestações e sentimentos que ligam o território e os povos que o habitam, de forma que sua análise implica uma visão humana e social da realidade, não podendo se restringir a uma observação meramente quantitativa. Para Santos e Silveira (2008):

O sentido da palavra territorialidade como sinônimo de pertencer àquilo que nos pertence... esse sentimento de exclusividade e limite 
ultrapassa a raça humana e prescinde da existência de Estado. Assim, essa ideia de territorialidade se estende aos próprios animais, como sinônimo de área de vivência e de reprodução. Mas territorialidade humana pressupõe também a preocupação com o destino, a construção do futuro, o que, entre os seres vivos, é privilégio do homem (Santos e Silveira, 2008, p.19).

Se considerarmos que a territorialidade sugere a apropriação e o domínio de um espaço específico, bem como de seus recursos, é preciso reconhecer sua importância na construção de um grupo social. E, dentro dos espaços das comunidades tradicionais no Brasil, o esforço coletivo para ocupar, usar e controlar seu território e, principalmente, com ele identificadas, resistir até os dias atuais, mantendo assim o seu produto histórico. Tal situação vai ao encontro do pensamento de Souza (1995), quando afirma que a territorialidade remete a um campo de forças, onde se encontram e se confrontam diferentes agentes.

A afirmação é corroborada pela realidade hodierna do PNLM, uma vez que, além dos conflitos históricos que as comunidades que o habitam tradicionalmente sempre tiveram de enfrentar, as imposições das atuais políticas públicas ampliam ainda mais as territorialidades e estas, quando se superpõem e/ou se confrontam, fazem emergir disputas, opondo distintos sujeitos sociais.

A presença de conflitos faz parte da natureza do território, sendo este um espaço político por excelência, cuja criação está associada a relações de poder, domínio e controles políticos. Os territórios não são apenas espaços físicos, são também espaços sociais, espaços culturais, onde se manifestam as relações e as ideias, transformando em território até mesmo as palavras (Fernandes, 2005). As relações conflituosas, porém, recrudescem em determinado território, quando nele se estabelecem relações de poder que nem sempre se coadunam com os interesses dos atores sociais na utilização do território como um espaço de realização dos seus mais específicos desejos.

Um conflito pode ser "esmagado" ou pode ser resolvido, entretanto, a conflitualidade não. Nenhuma força ou poder pode esmagá-la, chaciná-la, massacrá-la. Ela permanece fixada na estrutura da sociedade, em diferentes espaços, aguardando o tempo de volta, das condições políticas de manifestação dos direitos (Fernandes, 2005). Justamente por isso, em face da complexidade, é perceptível o desafio de desenvolver ações que possibilitem uma redução das dificuldades vividas pelos atores inseridos 
nesse contexto, ainda mais quando não há reciprocidade no diálogo entre as partes envolvidas.

Acreditamos, assim, que a análise dos conflitos ambientais, sob a ótica das territorialidades, pode favorecer a compreensão das relações entre sujeitos, interesses e poderes implicados na disputa, bem como do sistema social e de sua história como um todo.

\section{As Comunidades Tratada de Cima, Tratada de Baixo e Buritizal}

Buritizal, povoado cuja denominação se deve à abundante presença de uma palmeira muito alta (Figura 2), o buriti (Mauritia flexuosa), conta com 22 famílias, enquanto em Tratada de Cima e Tratada de Baixo vivem, respectivamente, 17 e 35 famílias, distantes cerca de um quilômetro do primeiro.

Tendo em vista estarem localizadas um pouco mais longe do mar, as três comunidades, em lugar da pesca, dedicam-se principalmente à agricultura de subsistência, cultivando milho, mandioca, arroz, feijão, maxixe, abóbora e quiabo no período chuvoso e, na época de estiagem, melancia e mandioca. Outra atividade presente em praticamente todas as comunidades é o artesanato, com a utilização da fibra do buriti para a produção de redes e de uma variedade de objetos, bastante apreciado pelos turistas. "O artesanato produzido nos Lençóis Maranhenses a partir da fibra do buriti (Figura 3) é único no país e configura um importante traço cultural da população da região" (Saraiva e Sawyer, 2007). O turismo, por sua vez, é uma atividade igualmente importante nas dependências do PNLM, visto que as características naturais do parque representam o principal apelo turístico do Maranhão, atraindo pessoas do mundo inteiro.

Segundo a legislação que regulamenta os parques nacionais, especificamente a lei que instituiu o SNUC, no que tange à atividade turística nessas áreas, deveria ser desenvolvido o turismo ecológico, aquele que visa à conservação do ambiente e promove o bem-estar das comunidades do lugar. No entanto, em vista da carência dos próprios mecanismos de fiscalização das atividades, o turismo não tem sido promovido nos Lençóis Maranhenses como preconizam os documentos legais. 


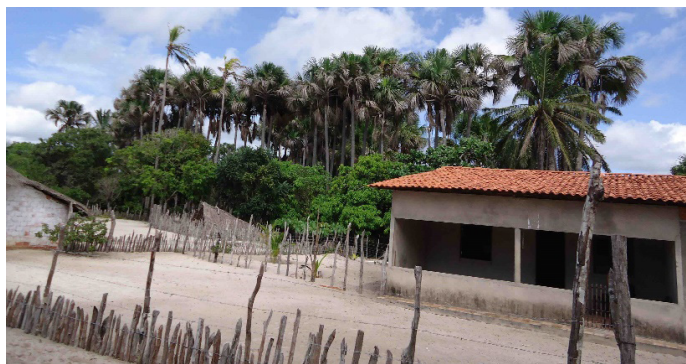

Figura 2 - Comunidade Buritizal

Fonte: Terra, 2016

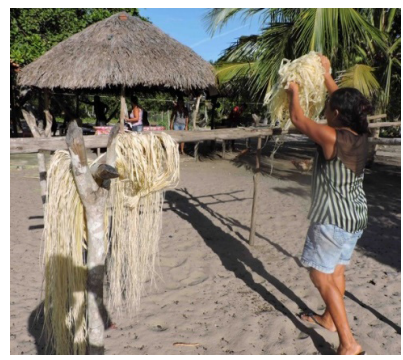

Figura 3 - Preparação da fibra do buriti para 0 artesanato Fonte: Terra, 2016

Dessa forma, uma atividade que poderia significar uma alternativa às práticas consideradas antiecológicas, alvo das proibições impostas pela legislação, com grande potencialidade de transformar os comunitários em aliados de primeira ordem na busca de práticas mais condizentes numa área de preservação, estranhamente não é pensada nessa perspectiva, uma vez que exclui os mais afetados pelo processo, comprometendo sua sobrevivência. O distanciamento entre a política sobre as UC e os pressupostos para se desencadear o processo de desenvolvimento em comunidades locais favorece, portanto, o surgimento de conflitos entre elas e a política de conservação da biodiversidade.

Conflitos socioespaciais nas Comunidades Tratada de Cima, Tratada de Baixo e Buritizal

O PNLM padece de um “pecado original”, uma vez que as políticas de sua criação, levadas a cabo pelo poder público, foram realizadas com pouca ou nenhuma participação da população que nele habitava/habita, ou que fazia/faz uso dos seus recursos como meio de subsistência, originando o mais crítico conflito da atualidade nessa unidade. A definição da área como UPI, à revelia da população local, teve profunda repercussão na vida dos comunitários, tendo em vista que a ocupação desse território não é recente, mas decorre de um processo histórico carregado de territorialidades, construídas ao longo de gerações que desenvolveram ali um gênero de vida específico.

De acordo com José Vale ${ }^{3}$, o parque foi criado durante a vigência do governo militar, período em que os processos não eram conduzidos de 
forma democrática e as decisões vinham de cima para baixo, portanto, sem que houvesse qualquer participação popular. Tampouco participaram do processo os órgãos públicos das esferas estadual e municipal, ou seja, até mesmo a prefeitura de Barreirinhas, município onde está localizada a maior parte do parque e que mantém maior relação com as comunidades, esteve complemente alheia às discussões acerca de sua implantação. As informações sobre ele eram bastante restritas e, quando as pessoas se deram conta, já estavam morando dentro de uma Unidade de Proteção Integral, sem saber das implicações disso no seu dia a dia.

Segundo os comunitários do PNLM e alguns dos seus representantes, a partir da criação do PARNA, os moradores foram impactados pela ação por vezes truculenta de alguns agentes públicos. Sem nenhum conhecimento sobre a nova situação legal de suas antigas posses, ou sobre as novas normas restritivas ao uso dos recursos, muitos passaram a se sentir numa condição de clandestinidade, num contexto renovado de suspensão de direitos, e não viram outra solução senão abandonar a área. Antes, marginalizados das políticas públicas e do mercado, atualmente convivem com a imposição de uma situação de total suspensão de direitos.

Por força da imposição legal, os camponeses que permaneceram no parque passaram a ter de incorporar compulsoriamente novos hábitos e a estabelecer novas formas de relação com a natureza. Dessa metamorfose emergiram novos conflitos de interesses, uma vez que as demandas de preservação da natureza se contrapõem às necessidades de sobrevivência dos grupos humanos que ali estão territorializados.

Desde a implantação do PNLM até os dias atuais, os comunitários têm, em relação aos agentes institucionais, uma forte desconfiança, apesar de que, já há bastante tempo, esse estado de tensão inicial tem sido substituído gradativamente por uma opção de negociação e colaboração. Em que pesem os avanços conquistados, os moradores são ainda interpretados pelos agentes institucionais de modo exageradamente tutelar, e a essa interpretação respondem responsabilizando-se apenas por conferir legitimidade a seus porta-vozes, geralmente alheios ao grupo social ao qual pertencem.

Além dos desajustes gerados pelo que denominamos de "pecado original”, várias atividades se desdobram em conflitos ambientais no PNLM, as principais ocasionadas pela utilização inadequada dos recursos naturais - incêndios, desmatamentos, extrativismo (vegetal, animal e mineral), agricultura predatória, pecuária extensiva, ocupação irregular 
-, além de outras, de uso público, como o rali, o banho, o camping, a caminhada, os passeios náuticos, o surfe, o windsurfe etc. Completam o cenário a indefinição fundiária e a falta de aprovação definitiva do plano de manejo.

O problema maior, todavia, verificado imediatamente após a criação das UC, refere-se à restrição do uso de recursos naturais, o que atinge desfavoravelmente as atividades desenvolvidas dentro delas e também em suas vizinhanças. A criação de uma área de proteção integral, com as normas restritivas ao uso de recursos naturais como opção por um tipo de política de conservação da biodiversidade, causa impactos negativos e pode inviabilizar as atividades camponesas, como a agricultura e/ou a pesca artesanal.

De acordo com Porto-Gonçalves (2006, p. 15), as soluções técnicas acabam por ignorar que o sistema técnico inventado por qualquer sociedade traz embutido nele mesmo a sociedade que o criou, com as suas próprias contradições. Ao mesmo tempo, os grupos sociais não respondem automaticamente e nem de modo uniforme aos problemas decorrentes da mudança social provocada pelo processo de institucionalização da conservação de ecossistemas, abrindo espaço, assim, para o confronto entre atores fortemente heterogêneos.

O conflito mais proeminente da atualidade no PNLM refere-se, então, àquele entre as comunidades tradicionais e o poder público, pelo fato de o ICMBio, em cumprimento à legislação, não permitir que os comunitários utilizem os recursos naturais da maneira tradicional como sempre o fizeram, por meio de práticas como o uso da madeira para diferentes fins, o sistema de roçados itinerantes, a criação de animais soltos, construção e ampliação de espaços de moradia etc.

Há relatos indignados de alguns comunitários, que classificam as ações do ICMBio como abuso de poder, não só devido à aplicação de multas pelo descumprimento da legislação, mas também a medidas como destruição de plantações, demolição de construções e proibição de reformas ou ampliações de moradias etc. De acordo com o presidente de uma associação de moradores de uma comunidade, "o ICMBio não maltrata, mas de certa forma persegue as famílias”. Já outro comunitário afirma que o "ICMBio quer proibir tudo que fazemos aqui, mas nós estamos reagindo contra eles, pois eles não trouxe (sic) qualquer benefício para nós, eles são contra a distribuição de energia no parque, isso é um problema para nós, principalmente para as pessoas doentes”. Do outro 
lado, os servidores do órgão se defendem, afirmando que, embora algumas atitudes extremadas sejam às vezes necessárias, elas são precedidas de muitas tentativas de esclarecimentos e de resolução dialogada das questões conflituosas.

A atividade turística nas dependências PNLM é outro elemento gerador e potencializador de situações conflituosas em torno dos diferentes atores sociais que se relacionam no parque.

No senso comum, o turismo é visto como uma atividade do setor terciário da economia que oferece a prestação de serviços aos seus consumidores, plenamente compatível com a preservação ambiental, geração de renda e com a manutenção da cultura não só das populações tradicionais que habitam as áreas de parques como também o entorno das UC. Sendo assim, haveria uma incontestável inter-relação entre o turismo, os comunitários e o meio ambiente, uma vez que este último constitui a 'matéria-prima' da atividade. “As áreas protegidas contemplam cada vez mais as necessidades do turismo, sobretudo numa perspectiva do contato direto com a natureza” (Silva e Souza, 2011, p. 30).

Segundo Goodwin (2002), há muito tempo já tem sido reconhecido o potencial do turismo para a cobertura dos custos de conservação e a promoção de oportunidades econômicas para as comunidades que vivem nas adjacências de patrimônios naturais. Para Luchiari (1999), por sua vez:

[...] ao inserir-se em uma determinada localidade, o turismo também agrega novos valores e formas de convívio social, substituindo ou transformando os antigos costumes e tradições locais, mostrando que o lugar encontra-se constantemente sendo recriado em suas relações com o mundo (Luchiari, 1999, p. 108).

Certamente, foi com base na natureza rentável do turismo (turismo ecológico e/ou ecoturismo) e subdimensionando-se os impactos negativos da atividade, que a administração do PNLM, contando com o apoio de setores da sociedade dos municípios do entorno diretamente interessados, defendeu sua implementação nas dependências do parque. Quando entrevistado, José Vale, secretário municipal de Agricultura, Pesca e Desenvolvimento do município de Barreirinhas, informou que o então "prefeito, ao perceber a potencialidade das belezas naturais que Barreirinhas possui, em especial a área que corresponde ao Parque Nacional dos Lençóis Maranhenses, começou a fazer o trabalho de divulgação, fomentando a possibilidade de pessoas conhecerem o parque". 
Do nosso ponto vista, porém, o turismo no PNLM representa um elemento a mais no agravamento do quadro de conflitos na área, uma vez que, ao mesmo tempo em que possibilita a inserção social, viabilizando as experiências de contato entre o turista e a natureza, provoca também a exclusão social, quando expulsa de seus domínios a população local (tradicional) e exige dela melhores condições econômicas para promover a aproximação com o ambiente, o que faz surgir novas necessidades e impele tais moradores a novos padrões de consumo, aumentando sua dependência de geração de renda.

Há que se indagar, com profundidade, sobre o real significado do turismo para o desenvolvimento nas UC, uma vez que ainda não se conta com uma resposta universal à questão sobre se e como o turismo contribui para o desenvolvimento local. É preciso, portanto, considerar como aspecto fundamental nesta reflexão buscar resposta à pergunta: quem ganha (ou tende a ganhar) e quem perde (ou pode perder) com essa atividade?

Reconhecendo os limites e impasses dessa questão, entendemos que a complexidade da natureza e da interação sociedade/natureza exige um trabalho que explicite a correlação entre os diversos componentes. Concordamos com Moysés Rodrigues (1997), quando afirma ser necessário buscar subsídios para uma análise mais complexa da atividade turística em espaço rural, o que implica levar em consideração novos elementos além dos já comumente relevados. Para a autora, que sugere enfrentar os desafios para mudar a abordagem como tem sido colocada, "considerar a atividade turística sustentável ou integrante da possibilidade do desenvolvimento sustentável é apenas desviar os termos da questão sem analisar a complexidade de uma atividade econômica que tem por base o consumo de paisagens naturais exóticas ou a história passada”. Ou seja, é necessário identificar, em cada caso, os diversos grupos de interesse, manifestos ou latentes, e divisar seus objetivos e estratégias/táticas.

De um modo geral, o turismo é uma atividade impactante em todas as suas modalidades, pois, para se desenvolver, depende de uma série de intervenções no espaço físico, como a construção de obras de infraestrutura, necessárias para o desenvolvimento do trade turístico. Em uma das entrevistas, o secretário municipal de Agricultura, Pesca e Desenvolvimento do município de Barreirinhas foi categórico ao afirmar que "foi somente com a construção da estrada (Rodovia MA-402) que o processo de visitação no Parque dos Lençóis ficou mais intenso". No entanto, como aponta Dias (2003, p. 87), "ocorre que os impactos negativos 
desse desenvolvimento podem gradualmente destruir os recursos ambientais dos quais depende o turismo", além de afetar outros âmbitos, como o social, o cultural, o econômico etc.

Dessa forma, entendemos que o turismo é um fenômeno social da modernidade e, no processo de implantação das UC como território, assume o papel de internalizar a chamada "natureza conservada" nos ditames do mercado, portanto, na privatização do uso da paisagem socialmente produzida. Considerando-se os aspectos de sua criação, os parques comumente atendem aos anseios de atores sociais ligados ao turismo, o que sem dúvida acirra ainda mais os conflitos, pois, de um lado, promovem a exclusão de comunidades que estiveram arraigadas nessas áreas, usando e ajudando a proteger os recursos naturais, ou sua inclusão de forma muito precária e, de outro, geram lucros para os agentes que dispõem de poder político e econômico, com uma visão mercadológica da natureza. É elucidativa a fala de uma moradora da comunidade de Buritizal:

Nós fazemos nossos artesanatos com a palha do buriti, extraímos e torramos a castanha do caju e depois vendemos para as pessoas que possuem barracas na lagoa, eles pagam um valor muito pequeno nos nossos produtos e vendem muito mais caro para os turistas, a nossa renda é muito pequena e incerta, vivemos com muita dificuldade aqui.

São muitas as evidências dos privilégios concedidos àqueles que detêm o poder político e econômico, em detrimento da comunidade local, que enfrenta problemas como o relatado pelo presidente da Associação de Moradores da Comunidade Tratada de Cima:

Com muita dificuldade, nós implantamos uma cooperativa com equipamentos para processar a castanha de caju. Com isso, esperávamos agregar maior valor no nosso produto, mas a cooperativa funcionou por pouco tempo, movida a gás, pois não temos energia elétrica, por causa que o ICMBio impede a entrada de energia no interior do parque.

Claro está que o turismo, como negócio, visa à obtenção de lucros; ao mesmo tempo, desenvolvê-lo implica manter a distribuição injusta da riqueza. Há que se chamar a atenção, no entanto, para as contradições inerentes à questão: ao mesmo tempo em que se propõe o desenvolvimento local, a preservação dos lugares e a proteção das culturas, procede-se à transformação do espaço em mercadoria e à massificação das culturas, atendendo às necessidades dos que vêm de fora e não as dos que ali habitam. Por outro lado, apesar de a expectativa principal do turismo ser 
o lucro e a concentração de riqueza e renda, é inegável sua potencialidade na criação de oportunidades de ganhos para os trabalhadores e os lugares mais pobres.

Assim, na contradição de que destrói e beneficia, o turismo pode ser visto positivamente, tal como na perspectiva da tese que, ao incorporar a antítese, o seu "contraponto", transforma-se em síntese, ponto e novamente contraposição da posição, marcando o processo evolutivo da sociedade.

\section{Considerações finais}

Ao término desta análise sucinta, reforçamos nossa convicção de que os conflitos na gestão ambiental e, especialmente, no gerenciamento das UC não são de todo negativos, uma vez que, através das relações conflituosas, podem surgir diversas formas de entendimento e de crescimento, dando origem às negociações e à procura por mecanismos para a regulação da gestão dessas áreas. Não é por acaso que a etimologia da palavra conflito remete ao prefixo latino $c o$ - que denota correlação - e ao verbo flictum - que significa choque, embate, oposição de forças. Convictos estamos, também, de que se torna cada vez mais evidente que a dissociação entre a política de criação das UC e as necessidades humanas no interior ou no entorno dessas unidades tem produzido efeitos negativos para o que se convencionou denominar "desenvolvimento local". Assim, a conservação dos recursos naturais do PNLM e a integridade da biodiversidade requerem uma conciliação entre tais necessidades e os objetivos de resguardar os elementos naturais.

De acordo com Diegues (2000), a concepção de conservação do mundo natural mais corrente entre os conservacionistas/preservacionistas é aquela que a entende como o manejo científico de ambientes naturais e seus recursos. E essa ação de manejo, caso seja entendida tão somente sob o ponto de vista científico, tende a perceber as relações entre as múltiplas sociedades e o mundo natural como análogas em todos os lugares, além de conjecturar que, para ser conservada, a natureza deve estar apartada das sociedades humanas, contrariando o modo de vida de povos que ainda dependem do espaço onde vivem e com o qual têm, portanto, uma relação direta (Diegues, 2000).

Consequentemente, faz-se necessário um esforço para ultrapassar antigas dicotomias e desconstruir a falsa oposição entre homem e natureza, rompendo assim as fronteiras artificiais que separam a questão ambiental 
da questão social, pois os problemas que envolvem as duas dimensões são ou estão intrinsecamente relacionados, o que torna complexo compreendêlos através de perspectivas que separam seus componentes essenciais.

Não se pode, enfim, conceber o meio ambiente como um dado à parte, mas como um elemento de cultura de uma comunidade, ou seja, como um processo de intercâmbio sociocultural gerado pelo homem e pela natureza. Não se pode, igualmente, admitir ações voltadas ao desenvolvimento, no que concerne ao meio ambiente, dissociadas do homem que o habita e, por conseguinte, de sua dinâmica cultural.

\section{Notas}

1 O presente artigo é um substrato do projeto de pesquisa Os Usos e (Ab)usos do Território nas Comunidades de Tratada de Cima, Tratada de Baixo e Buritizal no Parque Nacional dos Lençóis Maranhenses, vinculado ao Grupo de Estudos e Pesquisas em Geografia Agrária (GEPGA), da Universidade Estadual do Maranhão, e financiado pela Fundação de Amparo à Pesquisa e ao Desenvolvimento Científico e Tecnológico do Maranhão (FAPEMA), que desenvolvemos entre os anos 2014 e 2016 e cujo objetivo foi analisar em que medida a produção do território naquelas comunidades pode manter sua reprodutividade diante do conflito estabelecido entre preservação ambiental e produção agropastoril.

2 O topônimo, segundo o MMA/IBAMA (2004), remete-se à característica “[...] fisiográfica do Parque, por apresentar uma área de relevo plano, constituído por areias quartzosas marinhas e cordões de imensas dunas de coloração branca, as quais assemelham-se a "lençóis jogados sobre a cama'".

3 Secretário municipal de Agricultura, Pesca e Desenvolvimento do município de Barreirinhas (MA), na gestão 2013-2016.

\section{Referências}

ARRUDA, R. S. V. Populações tradicionais e a proteção. In: DIEGUES, A. C. (Org). Etonoconservação: novos rumos para a proteção da natureza nos trópicos. São Paulo: Hucitec, 2000.

BERKES, F. Sacred ecology: traditional ecological knowledge and resource management. Philadelphia; London: Taylor and Francis, 1999.

BRASIL. Lei no 9.985, de 18 de julho de 2000. Decreto no 4.940, de 22 de agosto de 2002. Institui o Sistema Nacional de Unidades de Conservação da Natureza SNUC. Brasília: IBAMA, Diretoria de Ecossistemas. 2002.

CASTRO, C. E. de. A política nacional de proteção da natureza e seus desdobramentos no território do Parque Nacional dos Lençóis Maranhenses. 
2012. Tese (Doutorado em Geografia) - Faculdade de Ciência e Tecnologia, Universidade Estadual Paulista, Presidente Prudente.

COLCHESTER, M. Salvaging nature: indigenous people and protected areas. In: GHIMIRE, K. B.; PIMBERT, M. P. Social change and conservation: environmental politics and impacts of national parks and protected areas. London: Earthscan Publications Limited, 1997.

DENKER, A. F. Métodos e técnicas de pesquisa em turismo. São Paulo: Futura, 2000.

DIAS, R. Turismo sustentável e meio ambiente. São Paulo: Atlas, 2003.

DIEGUES, A.C Etnoconservação da natureza: enfoques alternativos. In: DIEGUES, A.C. Etnoconservação: novos rumos para conservação da natureza. São Paulo: Hucitec, 2000.

DIEGUES, A. C. ARRUDA, R. S. V. (Org). Saberes tradicionais e biodiversidade no Brasil. Brasília: Ministério do Meio Ambiente; São Paulo: USP, 2001.

FERNANDES, B. M. Questão agrária: conflitualidade e desenvolvimento territorial. In: BUAINAIN, A. M. Luta pela terra, reforma agrária e gestão de conflitos no Brasil. Campinas: Editora da Unicamp, 2005.

GOODWIN, H. Local community involvement in tourism around national parks: opportunities and constraints. Current Issues in Tourism, v. 5, n. 3 \& 4, p. 338360, jun. 2002.

HAESBAERT, R. O mito da desterritorialização: Do "fim dos territórios" à multiterritorialidade. 2. ed. Rio de Janeiro: Bertrand Brasil, 2006.

HOLLING, C. S.; BERKES, F.; FOLKE, C. Science, sustainability and resource management. In BERKES, F.; FOLKE, C.. Linking social and ecological systems: management practices and social mechanisms for building resilience. Cambridge: Cambridge University Press, 1998.

UICN - The World Conservation Union. Parques y progreso. Washington: IUCN, 1993.

LUCHIARI, M. T. D. P. Turismo e meio ambiente na mitificação dos lugares. In: III ENCONTRO NACIONAL DE TURISMO COM BASE LOCAL, 1999, Manaus. Turismo em análise, 1999.

MINISTÉRIO DO MEIO AMBIENTE - MMA; INSTITUTO BRASILEIRO DO MEIO AMBIENTE E RECURSOS NATURAIS RENOVÁVEIS - IBAMA. Plano de Manejo do Parque Nacional dos Lençóis Maranhenses. São Luís, 2004.

MOYSÉS RODRIGUES, A. Desenvolvimento sustentável e atividade turística. In: BALASTRERI RODRIGUES, A. (Org.). Turismo e desenvolvimento local. São Paulo: Hucitec, 1997.

PEREIRA, D. B. Paradoxos do papel do Estado nas unidades de conservação. In: ZHOURI, A.; LASCHEFSKI, K.; PEREIRA, D. B. (Orgs.). A insustentável leveza da política ambiental: desenvolvimento e conflitos socioambientais. Belo Horizonte: Autêntica, 2005 
PORTO-GONÇALVES, C. W. A globalização da natureza e a natureza da globalização. Rio de Janeiro: Civilização Brasileira, 2006.

SANTOS, M; SILVEIRA, M. L. O Brasil: território e sociedade no início do século XXI. Rio de Janeiro: Record, 2008

SAQUET, M. A. Abordagens e concepções de território. São Paulo: Expressão Popular, 2007.

SARAIVA, N. A.; SAWYER, D. R. Análise do potencial econômico e socioambiental do artesanato do Buriti em comunidades tradicionais nos Lençóis Maranhenses. In: VI ENCONTRO NACIONAL DE ECONOMIA ECOLÓGICA. Anais... Fortaleza, 2007

SILVA, M. S. F.; SOUZA, R. M. Território usado em áreas protegidas e atrativos turísticos: exploração ou conservação ambiental? Revista Nordestina de Ecoturismo, Aquidabã (SE), v. 4, n. 2, p. 27-39, 2011.

SOUZA, M. J.L. O território: sobre espaço e poder, autonomia e desenvolvimento. In: Geografia: conceitos e temas. Rio de Janeiro, Editora Bertrand Brasil, 1995.

SPÓSITO, E. S. Geografia e filosofia: contribuições para o ensino do pensamento geográfico. São Paulo: Edunesp, 2004.

TERRA, Ademir. Os usos e (ab)usos do território nas comunidades de Tratada de Cima, Tratada de Baixo e Buritizal no Parque Nacional dos Lençóis Maranhense. Relatório Técnico. São Luís: Fapema, 2016.

Ademir Terra - Graduado em Geografia pelas Faculdades Integradas de Naviraí, com mestrado em Geografia pela Universidade Estadual de Maringá e doutorado em Geografia pela Universidade Estadual Paulista/ Presidente Prudente. Atualmente, é professor adjunto na Universidade Estadual do Maranhão (UEMA). 